\title{
Devamlı kombine hormon replasman tedavisinin uterin perfüzyon ve endometrial kalınlık üzerine etkisinin uterin arter Doppler bulguları ile değerlendirilmesi
}

\author{
The effect of continuous hormone replacement therapy on endometrial thickness and uterine perfusion with Doppler \\ sonography of the uterine arteries
}

\author{
Pınar Dündar Erenoğlu', Murat Ekin', Rana Karayalçın', Selda Karadeniz²
}

'Zekai Tahir Burak Kadın Sağlığı Eğitim ve Araştırma Hastanesi Kadın Hastalıkları ve Doğum Kliniği ${ }^{2}$ Zekai Tahir Burak Kadın Sağlığı Eğitim ve Araştırma Hastanesi Radyoloji Kliniği
Geliş tarihi: 01.07.2004 • Kabul tarihi: 14.02.2005

\section{Yazışma adresi \\ Dr. Murat Ekin}

Zekai Tahir Burak Kadın Sağlı̆ı Eğitim ve Araştırma Hastanesi Kadın Hastalıkları ve Doğum Kliniği, Ankara

Tel : : (312) 4196560

Faks : : (312) 4684133

E-posta : muratekin@hotmail.com
Amaç: Devamlı kombine hormon replasman tedavisinin (HRT) uterin perfüzyon ve endometrial kalınlık üzerine etkisinin Doppler sonografi ile değerlendirilmesi.

Materyal ve metod: Menapoz Kliniğine hormon replasman tedavisi almak için başvuran veya hormon replasman tedavisi almakta olan toplam 100 hasta çalışmaya dahil edildi. Hormon replasman tedavisi alan hastalarda yirmişer kişilik 4 gruba ayrıldı: Grup 1:2 mg estradiol + 1 mg norethisteron asetat; Grup 2: konjuge östrojen $0.625 \mathrm{mg}$ + medroksiprogesteron asetat $2.5 \mathrm{mg}$; Grup 3: konjuge östrojen $0.625 \mathrm{mg}+$ medroksiprogesteron asetat $5 \mathrm{mg}$; Grup 4: transdermal matriks sistemi $3.9 \mathrm{mg}$ östradiol $12.5 \mathrm{~cm} 2$ + doğal mikronize progesteron $100 \mathrm{mg}$. Kontrol grubuna (Grup 5) hormon replasman tedavisi almak için başvuran en az altı aylık amenoresi olup hormonal değerlendirilmesinde menapoz tespit edilen yirmi hasta dahil edildi. Hastalar kan östradiol seviyeleri, endometrial kalınlık ve uterin arter Doppler rezistivite indeksleri (RI) açısından değerlendirildiler. Bulgular: Kan östradiol seviyeleri açısından değerlendirildiğinde hormon replasman tedavisi alan gruplar arasında anlamlı farklılık olmamakla beraber kontrol grubu ile karşılaştııılıklarında anlamlı oranda yükseklik tespit edildi. Endometriyal kalınlık açısından değerlendirilme yapıldığında HRT alan olgularda endometriyal kalınlık kontrol grubuna oranla anlamlı olarak yüksek olmakla birlikte HRT alan gruplar arasında ortalama endometriyal kalınlıklar arasında istatistiksel fark tespit edilmedi. Benzer olarak, uterin arter Doppler RI ölçümleri, HRT alan gruplar arasında anlamlı farklılık oluşturmazken kontrol grubuna kıyaslandığında anlamlı olarak düşük bulundu.

Sonuç: Devamlı kombine hormon replasman tedavileri ile endometrial kalınlıkta patolojik değişiklikler olmadan uterin arter kan akımında anlamlı olumlu değişiklikler sağlanmaktadır. Tedavinin transdermal veya oral olması kan östrojen seviyesi yeterli olduğu sürece uterin arter kan akımı açısından anlamlı fark oluşturmamaktadır. Tedaviye eklenecek progestagenik ajan açısından sentetik veya doğal progestinler arasında uterin arter kan akımı açısından anlamlı fark tespit edilmemiştir.

Anahtar kelimeler: uterin arter, Doppler, endometrium, hormon replasman tedavisi

Aim: To investigate the effect of different continuous combined hormone replacement therapy modalities on endometrial thickness and uterine perfusion by Doppler sonograpy of the uterine arteries. Material andmethods: One hundred patients who were willing to have hormone replacement therapy and or still under different continuous combined hormone replacement therapy modalities were included. Patients that were under hormone replacement therapy were divided into four subgroups having 20 patients in each according to the type of hormone replacement therapy modalities. Group 1: $2 \mathrm{mg}$ estradiol $+1 \mathrm{mg}$ norethisterone acetate; Group 2: conjugated estrogen 0.625 $\mathrm{mg}+$ medroxyprogesterone acetate2.5 mg; Group 3: conjugated estrogen $0.625 \mathrm{mg}+$ medroxyprogesterone acetate $5 \mathrm{mg}$; Group 4: transdermal matrix system $3.9 \mathrm{mg}$ estradiol $12.5 \mathrm{~cm} 2+$ natural micronized progesterone $100 \mathrm{mg}$. Control group was consisted of women who were not under hormone replacement therapy, and suffering from amenorrhea duration of at least six months and diagnosed as menopause according to their hormonal status. Blood estradiol levels, endometrial thickness and resistivity index of uterine arteries with Doppler ultrasonography were investigated. Results: There was no significant difference in blood estradiol levels among study groups but a significant difference existed with the study groups compared to the controls. Endometrial thickness and resistivity index of the uterine arteries were also similar within the study groups but was found to be higher when compared with the controls.

Conclusion: Continuous combined hormone replacement therapies improve uterine perfusion without deleterious effect on endometrial thickness. There is no difference between transdermal and per oral administration of the hormone replacement therapy on uterine perfusion correlated to blood estradiol levels. Also there is no difference in the type of progestins added to the therapy on the uterine perfusion

Key words: Doppler of the uterine arteries, endometrium, hormone replacement therapy 
Tablo 1. Bulguların gruplara göre değerlendirilmesi.

\begin{tabular}{|c|c|c|c|c|c|}
\hline Grup & Yaş (yıl) & $\begin{array}{l}\text { Menapoz süresi } \\
\text { (ay) }\end{array}$ & Kan östrojen & $\begin{array}{l}\text { Endometriyal kalınlık } \\
(\mathrm{mm})\end{array}$ & Uterin arter $R I$ \\
\hline Grup 1 & $54.1 \pm 2.1$ & $27.9 \pm 12.3$ & $46.2 \pm 5.1$ & $5.00 \pm 0.86$ & $0.77 \pm 0.18$ \\
\hline Grup 2 & $53.5 \pm 2.8$ & $28.1 \pm 12.4$ & $45.8 \pm 4.6$ & $4.90 \pm 0.97$ & $0.77 \pm 0.25$ \\
\hline Grup 3 & $54.1 \pm 2.0$ & $28.2 \pm 10.2$ & $47.6 \pm 4.2$ & $5.05 \pm 1.05$ & $0.76 \pm 0.15$ \\
\hline Grup 4 & $54.3 \pm 1.9$ & $29.9 \pm 10.5$ & $47.5 \pm 4.1$ & $5.00 \pm 1.10$ & $0.76 \pm 0.15$ \\
\hline Grup 5 & $53.7 \pm 2.1$ & $28.0 \pm 11.9$ & $23.6 \pm 2.3$ & $2.35 \pm 0.49$ & $0.86 \pm 0.16$ \\
\hline
\end{tabular}

Postmenopozal dönemde endojen östrojen yapımının azalması; erken dönemde çeşitli psikiyatrik, vazomotor instabilite ve genitoüriner sistem bulgularına, geç dönemde ise osteoporoz insidansında artışa neden olmaktadır. Özellikle kombine östrojen + progestin kullanımı ile ilgili yakın zamanda derin ven trombozu, pulmoner emboli meme kanseri açısından küçük ama kesin bir risk artışı ortaya konulmuştur. Aynı çalışmalar kemik erimesi ve kolorektal kanserler için mutlak riskte azalma tespit etmiştir (1-3).

Postmenopozal dönemde uygulanacak hormon replasman tedavisi (HRT) ile endojen sentezi azalmış olan östrojen yerine konularak vazomotor semptomlar ve osteoporoz riski azaltılabilmektedir.

Postmenopozal dönemde hormon replasman tedavisi alan hastalarda; noninvaziv bir yöntem olan Doppler ultrasonografi ile uterin arter direnç değişikliklerini belirleyerek değişik hormon replasman tedavilerinin direkt ve indirekt olarak endometrium üzerine olan etkilerinin gösterilmesi amaçlandi.

\section{Gereç ve Yöntem}

Hastanemiz menapoz kliniğine hormon replasman tedavisi almak için başvuran veya hormon replasman tedavisi almakta olan toplam 100 hasta prospektif olarak değerlendirildi. Çalışmaya dahil edilme kriteri olarak en az bir yıldır devamlı HRT belirlendi. Hormon replasman tedavisi alan hastalarda yirmişer kişilik 4 gruba ayrıldı:

Grup 1: $2 \mathrm{mg}$ estradiol + 1 mg norethisteron asetat, Grup 2: konjuge östrojen $0.625 \mathrm{mg}+$ medroksiprogesteron asetat $2.5 \mathrm{mg}$, Grup 3: konjuge östrojen $0.625 \mathrm{mg}+$ medroksiprogesteron asetat $5 \mathrm{mg}$, Grup 4: transdermal matriks sistemi $3.9 \mathrm{mg}$ östradiol $12.5 \mathrm{~cm} 2+$ doğal mikronize progesteron $100 \mathrm{mg}$. Kontrol grubuna hormon replasman tedavisi almak için başvuran en az altı aylık amenoresi olup hormonal değerlendirilmesinde menapoz tespit edilen yirmi hasta dahil edildi.
Hastalarda kan estradiol seviyelerinin tespiti için aç olarak antekübital venden alınan kan Hastanemiz hormon labaratuvarında "Imulite 2000 RIA kit" ile ölçüldü.Tüm hastalarda transvajinal ultrasonografi ile pelvik patolojiler (myoma uteri, adeksiyel kitle vb.) ekarte edildikten sonra endometrial kalınlık ve uterin kan akımı açısından Doppler ultrasonografi ile değerlendirildiler. Ölçümlerde transvajinal 6.5 MHz probu olan Toshiba Povervision 6000 ultrasonografi cihazı kullanıldı. Probun hareketleri ve cihazın tarama planı değiştirilerek uterus, damarlar, endometriyum, adneksiyal alanlar, "Douglas" boşluğu ve diğer pelvik yapılar sistematik olarak değerlendirildi. Endometriyum kalınlığı longitüdinal planda her iki endometriayal duvarın dıştan dışa ölçümüyle değerlendirildi. Uterin arter renkli Doppler ile uterusun lateral servikal bölgesinde vizüalize edildikten sonra ortalama $0^{\circ}$ açıyla ard arda gelen üç doğru değerlendirmiş Doppler dalga görüntüsü elde edilerek rezistivite indeksi (Sistol - diastol sonu/sistol) sağ ve sol uterin arterler için değerlendirildi. Bulguların istatistiksel analizi "SSPS 10.0 for Windows release" paket programı kullanılarak One -Way ANOVA yöntemi ile yapıldı.

\section{Bulgular}

Çalışmaya dahil edilen gruplarda hastaların yaşları 49-58 arasında değişmekteydi. Hastaların yaş ortalamalar1, ortalama menapoz süreleri (ay) ve HRT alan gruplar için HRT aldıkları süreler (ay) açısından değerlendirildiklerinde aralarında istatistiksel olarak anlamlı farklılık tespit edilmedi $(p>0.05)$. Gruplar, kan estradiol seviyeleri açısından değerlendirildiğinde HRT alan gruplar arasında anlamlı farklılık olmamakla beraber kontrol grubu ile karşılaştırıldıklarında anlamlı oranda yüksek tespit edildi $(\mathrm{p}<0.05)$. Endometriyal kalınlık açısından değerledirilme yapıldığında HRT alan olgularda endometriyal kalınlık kontrol grubuna oranla anlamlı olarak yüksek olmakla birlikte HRT alan gruplar arasinda ortalama endometriyal 
kalınlıklar arasında istatistiksel fark tespit edilmedi. Benzer olarak uterin arter Doppler RI ölçümleri HRT alan gruplar arasında anlamlı farklılık oluşturmadan kontrol grubuna kıyaslandığında anlamlı olarak düşük tespit edildi. (Tablo 1), (Şekil 1,2,3).

\section{Tartışma}

Hormon replasman tedavisinin uygulanması, günümüzde menapozu takip eden dolaşımdaki azalan östrojen seviyesine bağlı gelişen vazomotor yakınmaların giderilmesi için tavsiye edilmektedir. Östrojenin arterler üzerinde direkt vazodilatatör etkisi vardır (4). Vasodilatatör etkinin vasküler düz kas üzerinde kalsiyum kanal bloku ile olduğu düşünülmektedir (5). Bu vazodilatatör etki özellikle östrojen reseptörlerinin yoğunlaştığ 1 serebral, karotid ve uterin arterler üzerinde gözlenmektedir (5-7). Yapılan çalışmalarda menapoz süresinin uzunluğu ile doğru orantılı olarak uterin kan akımındaki direncin arttığı gösterilmiştir (8). Menapozda endometrium ve vasküler yatak açısından hormon replasman tedavisinin güvenliği, östrojen ve progesteronun optimal dengesine bağlıdır. Siklik hormon replasman tedavilerinde sılklıkla gözlenen çekilme kanaması uzun süre endometriyumun kötü etkilenmediğinin bir göstergesi olarak düşünülmekle birlikte Sturdee ve ark. (9) tarafından yapılan çalışma bu tezin aksine çekilme kanamasının endometrial hiperplaziyi ekarte etmediğini bildirmektdir. Yine Exacoustos ve ark. (10) göre siklik hormon replasman tedavisininin belirli evrelerinde uterin kan akımı değişmemektedir. Bu sebeple siklik tedaviye nazaran devamlı kombine tedavinin daha güvenli olduğu düşünülmektedir. Çalışmamızda devamlı hormon replasman tedavisi alan hasta gruplarında tedavi almayan kontrol grubuna oranla uterin arter perfüzyonunda anlamlı derece artış olduğunu tespit ettik. Yine hormon replasman tedavisi alan grupta endometriyal kalınlık kontrol grubuna oranla anlamlı olarak kalın tespit edilmekle birlikte patolojik düzeyde endometriyal kalınlık gözlenmedi. Bunu hastaların devamlı hormon replasman tedavisi protokolüne uyumlarına bağlamak mümkündür; zira hastaların hormon replasman tedavisi alan kısmında beklenenden yüksek kan E2 seviyelerine rastlanılmamaktadır. Endometriyal kanser riski nedeniyle histerektomi olmamış kadınlarda östrojenin proliferatif uyarısını dengelemek amaciyla tedaviye progesteron eklenmektedir (11-13). Ancak eklenen progestogenlerin östrojenin kardiyovasküler sistem üzerine olan faydalı etkisini azaltığı ileri sürülmüştür $(11,12)$. Progesteronun bu etkisini renin sekresyonunda artış prostosiklin/ tromboksan oranında azalma veya östrojene bağlı nitröz oksit oluşumunu engelleyerek gösterdiği bazı araştırmacılar tarafından ileri sürülmüştür (14). Ancak fertil kadınlarda ya-

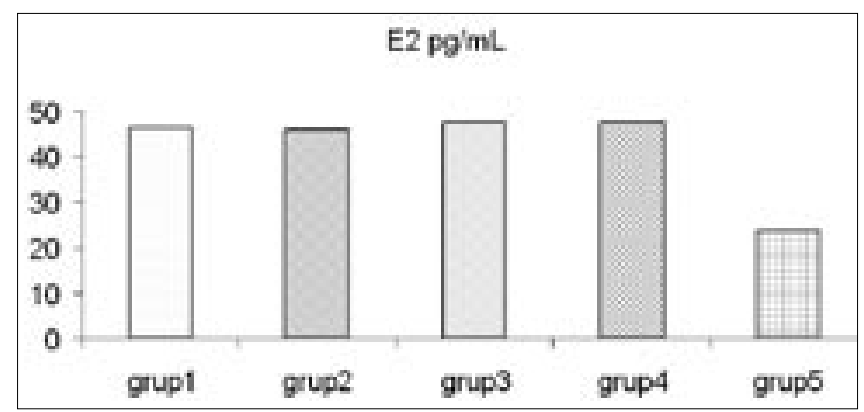

Şekil 1. Gruplar arası kan E2 seviyelerinin karşılaştııııması

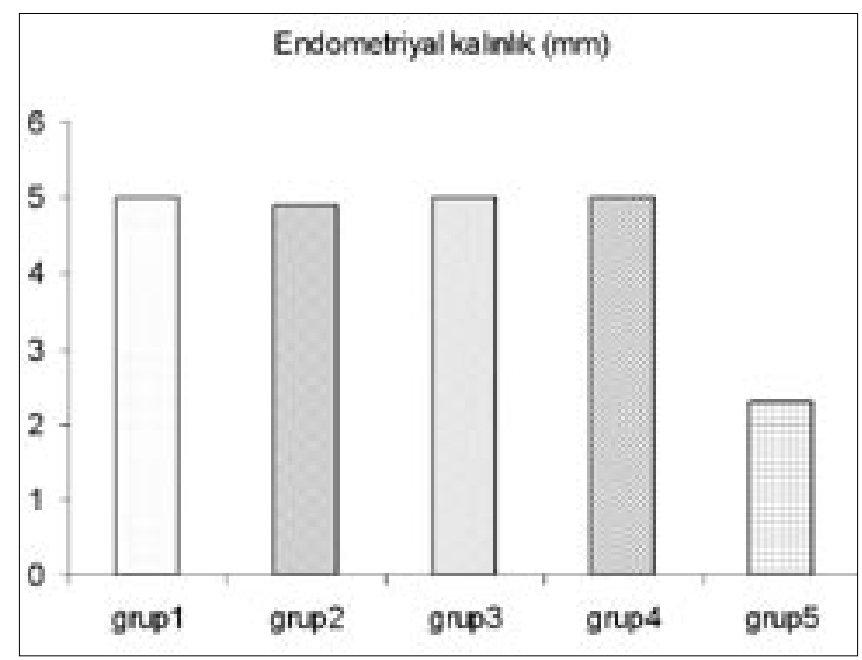

Şekil 2. Gruplar arası endometriyal kalınlık ölçümlerinin karşılaştırııması

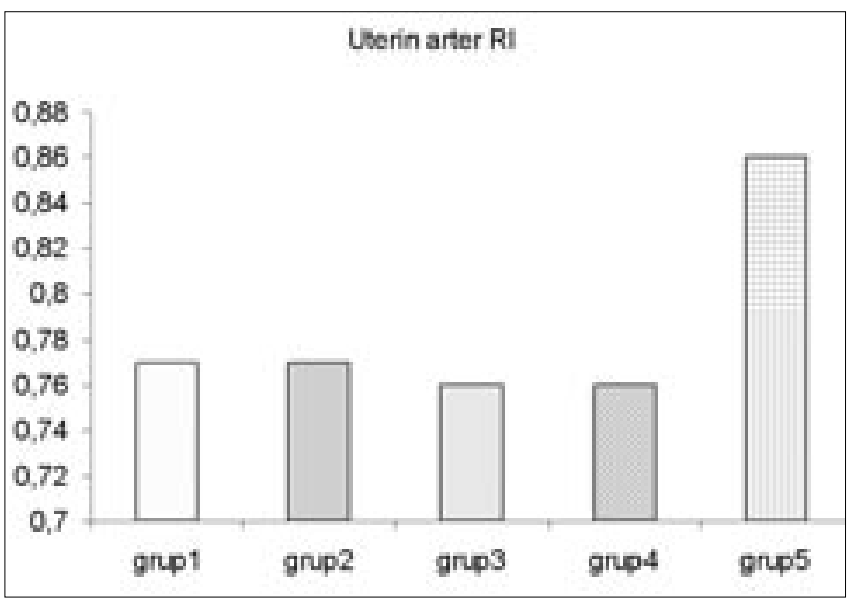

Şekil 3. Gruplar arası uterin arter RI seviyelerinin karşılaştırılması

pılan çalışmalar uterin arterlerde en düşük direncin luteal fazın pik yaptığı dönemlere rastladığı gösterilmiştir (11). Buda doğal progesteronların östrojen etkisini bozmadığını düşündürmektedir. Başlangıçta yapılan bazı çalışmalarda ardışı olarak $(11,13)$ ve devamlı intrauterin uygulanan $(14,15)$ sentetik progestojenlerle uterin arter kan akımında direnç artışı bildirilmekle birlikte yakın zamanda yapılan çalışmalar vajinal yolla uygulanan doğal progestinler ve didrogesteron için siklik tedavilerde minör kan akımı de- 
ğişiklikleri bildirilmektedir. Exacoustos ve ark. (10) diğer yapılan çalışmaları göz önüne alarak hem sentetik hem de doğal progestinlerin östrojenin uterin arterler üzerine olan vazodilatatör etkisine anlamlı bir azalma oluşturmadıklarını bildirmişlerdir $(16,17)$. Yine de anti-östrojenik etki progesteronun tipi yanında etki süresi ve dozu ile de etkili olabilir (18). Çalışmamızda hormon replasman tedavisi alan gruplar içerisinde progestogen olarak norethisteron asetat, medroksiprogesteron asetat ve mikronize progesteron mevcut olup sentetik ve doğal progestinler arasında uterin kan akımı açısından anlamlı fark tespit edilmemiştir. Yine medroksi progesteron asetatın $2.5 \mathrm{mg}$ ve $5 \mathrm{mg}$ tedavi seçenekleri arasındada anlamlı fark tespit edemedik. Penotti ve ark. (19) benzer olarak medroksi progesteron asetat içeren hormon replasman tedavisi protokollerinde uterin arter kan akımında değişiklik tespit edememişlerdir. Östrojen tedavisine eklenecek progestin sentetik veya doğal olsun endometriyal kalınlık üzerine anlamı ölçüde koruyucu etki yapmaktadır ve bulgularımıza göre hormon replasman tedavisi almayan gruba kıyasla uterin kan akımında anlamlı artış gözlenmiştir. Grupların sayısal olarak kısıtlı olması nedeniyle bu konu üzerinde daha geniş sayıda hasta içeren kontrollü çalışmalara gerek olduğuna inanıyoruz. Çalışmamızda oral ve transdermal hormon replasman tedavileri ile uterin arter perfüzyonunda anlamlı bir farkın olmadığını gördük. Cacciatore ve ark. (17) çalışmamızla benzer olarak 27 oral 31 transdermal hormon replasman tedavisi alan iki grubu karşılaştırmışlar ve bir yıllık tedavi sonrası iki gruptada uterin arter kan akımında eşit oranda anlamlı artış tespit etmişlerdir. Bu çalışmada hormon rep-

\section{Kaynaklar}

1. Rossouw JE, Anderson GL, Prentice RL, et al. Risks and benefits of estrogen plus progestin in healthy postmenopausal women: principal results from the Women's Health Initiative randomized controlled trial. J Am Med Assoc 2002; 288:321-33.

2. Chlebowski RT, Hendrix SL, Langer RD, et al. Influence of estrogen plus progestin on breast cancer and mammography in healthy postmenopausal women. The Women's Health Initiative Randomized Trial. J Am Med Assoc 2003; 289:3243-53.

3. Million Women Study Collaborators. Breast cancer and hormone replacement therapy in the Million Women Study. Lancet 2003; 362:419-27.

4. Vyas S, Gangar K. Postmenopausal oestrogens and arteries. Br.J.Obstet.Gynecol. 1995; 102:942-6.

5. Bergqvist A, Bergqvist D, Ferno M. Estrogen and progesterone receptors in vessel walls. Biochemical and immunochemical assays. Acta Obstet.Gynecol Scand. 1993; 72:10-6.

6. Bourne TH, Hillard T, Witehead M et al. Oestrogen,arterial status and postmenopausal women. Lancet. 1990; 335:1470-1.

7. Gangar KF, Viyas S, Witehead MI. Pulsatility index in internal carotid artery in relation to transdermal öestradiol and time since menopause. Lancet. 1991; 338:839-42. lasman tedavileri siklik olmakla birlikte daha önce yapılan çalışmalarda siklik tedavilerde uterin arter kan akımının değişik fazlarda etkilenmediği gösterilmiştir. Çalışmamızda iki grup arasında ortalama östradiol seviyeleri benzer olup kan östradiol seviyeleri ile uterin kan akımı arasındaki pozitif korelasyon olduğu gözlenmektedir. Predanic ve ark. (20) 106 hormon replasmanı alan hasta grubunda kompliansı iyi ve kötü olan hastaları kan östradiol seviyeleri ve uterin arter kan akımı açısından değerlendirmiş ve kompliansın bozuk olduğu grupta kan östradiol seviyeleri ile doğru orantılı olarak uterin kan akımını kompliansı yüksek guruba nazaran anlamlı olarak düşük tespit etmişleridir.

Transvajinal sonografi ile birlikte renkli Doppler uterin arter kan akımı değerlendirmesi değişik tedavi protokollerinin etkinliğini ve hastaların hormon replasman tedavisine uyumunun değerlendirilmesinde uygun bir metod olarak kullanılabilir. Özellikle değişik hormon replasman tedavisi protokollerinde hepatik metabolizmanın arttığ 1 , sigara ve alkol veya psikotropik ilaç alan hasta gruplarında hormon replasman tedavisine cevabın değerlendirilmesinde kullanilabilir.

Devaml 1 kombine hormon replasman tedavileri ile endometrial kalınlıkta patolojik değişiklikler olmadan uterin arter kan akımında anlamlı olumlu değişiklik sağlanmaktadır. Tedavinin transdermal veya oral olması kan östrojen seviyesi yeterli olduğu sürece uterin arter kan akımı açısından anlamlı fark oluşturmamaktadır. Tedaviye eklenecek progestagenik ajan açısından sentetik veya doğal progestinler arasında uterin arter kan akımı açısından anlamlı fark tespit edilmemiştir.

8. Bekavac I, Kupesic S, Mihaljevic D et al. Vascular impedeance of uterine, inferior vesicle and ophtalmic arteries in postmenopausal women receiving hormone replacement therapy. Comperative doppler study. Croat med. J. 2000; 41:3:235-9.

9. Sturdee DW, Barlow DH, Urlich LG et al. Is the timing of withdrawal bleeding a quide to endometrial safety during sequential oestrogen progesterone replacement therapy? Lancet 1994; 343:979-82.

10. Exacoustos C, Lello S, Caporale E, et al. Monitoring of hormone replacement therapy in postmenopausal women by transvaginal sonography. And color flow doppler: Study in different phases of sequential therapy. Fertil. Steril 1999; 71:536-43.

11. Bourne TH, Hillard T, Whitehead M, et al. Transvaginal ultrasonography with color flow imaging to monitor hormone replacement threpy in postmenopausal women. Br.J. Radiol 1991; 64:657-61.

12. Hillard TC, Bourne TH, Whitehead MI et al. Differential effects of transdermal oestradiol and sequential progestogens on impedance to flow with in the uterine arteries of postmenopausal women. Fertil. Steril. 1992; 58:959-63.

13. Persson I, Adami HO, Lindberg BS et al. Characteristics of oestrogen treated women. Acta Obstet.Gynecol. Scand. 1983; 62:297-302. 
14. Ylikorkala O, Puolakkala J, Viinikka L. Vasoconstictory tromboxane a 2 and vasodilatotory prostacyclin in climacteric woman. Effect of oestrogen progesterone therapy. Maturitas 1984; 5:201-5.

15. Jarvella I, Raudaskoski T, Tekay A et al. Effect of the levonorgestrel relaasing intrauterine system on the uterine artery Pulsatility index in postmenopaual hormone replacement therapy. Ultrasound. Obstet. Gynecology. 1997; 10:350-5.

16. Bonilla-musoles F, Marty MC. Effect of hormone replacemet therapy on uterine blood flow and endometrial status in postmenopausal women. In:Fleicher Kurjak A, Granberg S, editors Ultrasound and the endometrium Newyork:Partenon 1997; 97-108.

17. Cacciatore B, Paakkari I, Toivonen J, et al. Randomized comparison of oral and transdermal hormon replacement on carotid and uterin artery resistance to blood flow. Obstet. Gynecol.1998; 92:563-8.
18. Zalud I, Conway C, Schulman $\mathrm{H}$ et al. Endometrial and myometrial thicknes and uterine blood flow in postmenopausal women. The influence of hormone replacement therapy and age. J.Ultrasound med.1993; 12:737-41.

19. Penooti M, Farina M, Sironi L, et al. Long term effects of postmenopausal hormone replacement therapy on pulsatility index of internal carotid and middle cerebral arteries. Menopause 1997; 4:101-4.

20. Predanic M, Ujevic B, Aleem F et al. Correlation serum oestrogen levels with uterine and carotid arteries flow in post menopausal women on hormone replacement therapy. Croat Med. J. 1998; $39: 2: 181-4$ 